Journal of Social Sciences 5 (4): 471-473, 2009

ISSN 1549-3652

(C) 2009 Science Publications

\title{
The Development of Natural Pigments in Esaan Folk Wisdom for Usage of Painting
}

\author{
${ }^{1}$ Suchat Sukna, ${ }^{1}$ Sastra Laoakka and ${ }^{2}$ Thaksina Krairach \\ ${ }^{1}$ The Research Institute of Northeastern Art and Culture, Mahasarakham University, Thailand, 44000 \\ ${ }^{2}$ Department of Community and Family Nursing, Srimahasarakham Nursing College, Thailand, 44000
}

\begin{abstract}
Problem statement: The objectives of this research were: (1) History and background of pigments from natural material in Esaan painting, (2) current condition and problems of pigments from natural material in painting work and (3) develop pigments from natural material for painting work usage. Approach: The instrument consisted of the observation form, interview form, focus group discussion and workshop record form. The sample consisted of the persons involved in the pigments usage from natural material for painting work including the academic persons, painters, local scholars, monks and general persons. Data were concluded based on objective and categorized into groups based on research objectives. Data were investigated by Triangulation Technique and analyzed. The findings were presented by analytic description. Results: (1) Historical background of pigments from natural material in Esaan painting, found in 3 periods including pre-historical period, historical period and contemporary period, with loosed relationship regarding to material and technique. In pre-historical period, the pigments were used in painting the cave art or pattern color writing on pottery. The popular color was red called Red Ochre for transferring people's belief ritual, lifestyle and decoration. For historical period, pigments were used as written Buddha offerings by writing on Buddhism buildings as well as adding instruction of Dharma principles, developing pleasure and showing beauty. The local pigments from natural material obtaining from plant, animal and mineral mixing with chemical substance importing from China, would be used. For contemporary period, the pigments from natural material for showing traditional uniqueness for the added value. (2) Current situation, the colored painting was decayed as the time went by. The material used to be used still existed in locality. The problem was there were no research studies of material or usage of material in developing the added value in any aspect. (3) Development of pigments from natural material for painting work, started from the selection of quality pigment powder with appropriate attribute, developing the material to produce the equipment for producing as well as modern chemical substance to be mixed with, the same as that used to be used in industrial for producing the enamel substance in present time. Conclusion/Recommendations: For the factors of success in developing pigment from natural material for painting work usage. They were based on development of material and local technique to process depending on modern technology and improvement for better products in future.
\end{abstract}

Key words: Development, natural pigments, Esaan folk wisdom, painting

\section{INTRODUCTION}

Global community focused on using cultural dimension for country development by reviving, applying and constructing new things based on foundation of traditional wisdom and wisdom in producing pigments from natural material to use in painting work, found from pre-historic period in many places of the world including Esaan Region of Thailand. There was development transcending to contemporary period. For Esaan painting of pre-historic period, the red color was popular as major color for reflecting their belief, ceremony, lifestyle and decoration as the cave art and the writing pattern on pottery. The historic period in early Ratanakosin age, the painting on the wall of Buddhist chapel, temple, library for Buddhist sacred writing, or temple hall for offering as an offering to Buddha, classroom for teaching morals and ethics, pleasure and decoration. The painters would use pigment from natural material in local mixing with the material they bought from market. For contemporary period, the traditional wisdom was applied for the added value in economic, social and cultural aspects.

Corresponding Author: Suchat Sukna, Research Institute of Northeastern Art and Culture, Mahasarakham University, Thailand, 44000 
In recent situation, found that the colored paintings were dilapidated according to the time. While there were material using for drawing picture, but they weren't used for developing the added value. Therefore, the researcher would develop pigment from natural material in Esaan locality combining with various kinds of pigment or material bought from market in the present.

Purpose: In this research, the objective were to study: (1) history and background of pigments from natural material in Esaan painting, (2) current condition and problems of pigments from natural material in painting work, (3) development of pigment from natural material for painting work.

\section{MATERIALS AND METHODS}

Materials: Consisted of the observation form, interview form, focus group discussion and workshop record form. Popular sample: Consisted the persons who used natural pigment from natural material in performing Fine Art including academic persons, painters, village scholar, monk and general people. Methods: This research was Research and Development by using qualitative research. Data were collected from documents and filed study. They were concluded and categorized into groups based on research objectives and investigated by using Triangulation technique, analyzed and presented as an analytic description.

\section{RESULTS}

- The usage of natural material for Esaan painting work, occurred by pre-historical period. The Esaan Region found colored painting in the cave and shack cliff most in Thailand. Its age was approximately 3,000 years ago. Besides the colored painting on the cave wall, it was also painted on pottery including Ban Chieng colored painting pattern, Udontani Province. At the end of prehistorical period, about 2,300-1,800 years ${ }^{[5]}$. The popular color was red obtaining from Red Ochre. Red color occurred from the mixture of Hematite as soft content which could be easily ground and seen in general places of different regions all over the world ${ }^{[3]}$. Using pigments, they had to be ground from the lump of clay into powder mixing with material as clue obtaining from rubber, oil, bone marrow, or broiled water broiling from animal's skin as well as from egg mucus or honey bee. Not only the Red Ochre would be obtained but Red
Color would be also obtained from some kinds of latex such as Tuew plant as well as some kinds of fruit or blood. The usage of red color would be related to belief and ritual, offering sacrifice to super natural power, agriculture, merry and beautiful decoration. Historical period, about the early of Ratanakosin, the paintings were done on temple wall, Tripitaka hall, or temple hall of religious instruction. They were paintings related to Lanka Wong Doctrine of Buddhism combing to Tai-Lao Culture including to pay respect to ghost, behaving based on Heet-Kong. It was also believed that Pra Wes Cloth using in merit ceremony in the 4th month with drawing picture of stories of the former incarnations of the Lord Buddha, Wes Sanndon, from the beginning to the end of cloth, wrapping around for decorating temple hall, might be origin of writing picture on the temple wall in later period ${ }^{[1]}$. People would create the paintings for offering to Buddha Buddhism, using as a media in instructing Dharma, decorating for beauty and making audiences be joyful. Their technique would be writing powder pigments. There were 2 kinds of usage pigments including the pigments from China and pigments from natural material in locality such as plant, animal and mineral such as Red Ochre, Yellow Ochre, Indigofera, Shellfish Lime and charcoal powder. For contemporary period, found that Pulu villagers at Ban Chieng Sub-district, Nonghan District, Udon Tani Province, used Red Ochre to paint pottery in producing souvenir goods imitating pattern of colored writing container in Ban Chieng Style which was the creation of added value and proud feeling, attachment and unity both in family and community

- The present state of colored painting was in a bad condition according to the time passing by. For pigments from natural material which used to be used in Esaan painting work, they could be found in general local. The problems were there were no usages of material to create the added value and no research studied was conducted as well as the quality and characteristics of material were not improved

- Development of natural material which used to be used in Esaan painting, 5 kinds of material would be selected with appropriate characteristics on producing pigments, it was endure to the light, could be ground and had standard color shade including Red Ochre, Yellow Ochre, Indigofera, Shellfish Lime and Bone Charcoal, putting into process in producing pigments by modern machine and quality chemical mixture material. The 
producing process consisted of mixing, grinding and adjusting concentration or fluidity, adapting color and comparing color as the standard, controlling and improving quality from experimentation of all 5 colors, concluded that:

- $\quad$ Red Ochre, Yellow Ochre and Bone Charcoal were Inorganic Pigments as mineral with characteristic of high endurance to the light, could be grounded very well and had standard color can to use in painting work

- Indigofera was the organic pigment, although it could be ground very well, its endurance was less which could be improved by avoiding high sunlight and used the chemical material to enamel for maintaining the surface of product in order to use in painting work

- Shellfish lime (calcium carbonate), although it was an inorganic pigment which could be ground very well, it was no color substance. So, it wasn't appropriate to be used in painting work. But, it had an importance in using as the added substance which could make very color is more concentrated characteristic

\section{DISCUSSION}

The usage of pigments from natural material in Esaan painting shoed relationship of human beings and environment by applying natural resources for usefulness until collected and formed cultural model. It was supported by Santasombat ${ }^{[2]}$ explanation that the environmental condition and geo-ecology were related to the culture because they were factors determining evolution process in human's society and culture.

Specifically, Esaan painting in historical period was important in morality by inculcating Buddhism instruction. It was a well thought plan in developing happiness in society. It was supported by viewpoint of Samoson $^{[1]}$ that Esaan people believed in sin-merit. So, they draw the picture of "Tri- Bhume" on the wall outside the building to warn those who saw it, to suggest them to be aware of Dharma principles. Moreover, it reflected the art value as the statement of Professor Tangchloke ${ }^{[4]}$ that the art was the same as religious which could change people to have high conscience, help in inculcating human's spirit, mind and thought to be pure, fine and fond of a good way.

Development of natural material in Esaan local to use as pigment for painting work, it was the creation of added value for natural resources in locality based on improving, applying and constructing new things based on foundation of traditional painting wisdom so that the pigment would be alternative product for society, or apply the findings for developing and in other patterns in the future.

\section{CONCLUSION}

The Esaan paintings by natural material were found since pre-historical period, with development continuing until contemporary period including loosed relationship regarding to material, technique and pattern without direct transfer. But, they had common point as learning from natural learning and application.

The development of natural material as pigments using for painting work, had an importance from the selection of natural material with appropriate characteristics as well as using modern material, equipment and process. Although there were weak points in quality and attribute including little colored shade, light colored shade, the details and scattering were not consistent and viscous color. It had to take time in improving and developing to be better, or during using it could be added quality by using with other colors or combining other medium. The main point was that whether the performance would be good or not, it wasn't only depend on the color or characteristic of pigments it was also very much depended on the worker's knowledge, competency, skill, aptitude and usage technique.

\section{ACKNOWLEDGEMENT}

The researcher would like to thank his advisor for the advice, Office of Higher Education, Research Institute of Esaan Art and Culture, Mahasarakham University for providing Research Grant, the key informants and very one of related persons for supporting this study until it was completely finished.

\section{REFERENCES}

1. Samoson, P. and E. Sarn, 1998. Mural Paintings, Amarin Printing Group, Bangkok, ISBN: 9748359018.

2. Santasombat, Y., 2005. Human and Culture. 3rd Edn., Thammasat University, Bangkok, ISBN: 9745717819.

3. Sompeun, N., S. Khian, P. Phanang, T. Yuk, B. Nai and P. Thai, 2002. AP Graphic Design and Printing. Bangkok, ISBN: 9744175222.

4. Tangchloke, I., 2007. Teaching Guideline and Creation of High Painting. American Printing and Publishing, Bangkok, ISBN: 9789746411790.

5. Wongted, S., 2006. Phalang Lao Chao Isan Ma Chak Nai. Matichon, Bangkok, ISBN: 9743237542. 